\title{
Extensive calcification of the ligamentum flavum causing cervical myelopathy in a Caucasian woman
}

\author{
Milaine Roet ${ }^{1}$, Jochem K. H. Spoor ${ }^{1}$, M. de Waal ${ }^{2}$, Max J. Kros ${ }^{3}$, Sanjay B. Harhangi ${ }^{1}$ and Ruben Dammers ${ }^{1,4^{*}}$
}

\begin{abstract}
Calcification of the ligamentum flavum (CLF) can cause myelopathy due to spinal cord compression. Only several cases in Caucasian patients have been described. Neurological deterioration can only be stopped by surgical decompression. We report a 63-year-old Caucasian woman presenting with progressive pins-and-needles sensations in both hands, worsened by painful paresthesia in both lower extremities. MRI showed a dorsal compressive mass extending from C2 to Th3 vertebrae with myelopathy at the level of C6. A laminectomy was performed, which improved clinical symptoms. Histological examination showed CLF. Early recognition of CLF and early spinal cord decompression are needed to improve neurological outcome.
\end{abstract}

Keywords: Calcification of the ligamentum flavum (CLF), Cervical spine, Caucasian, Myelopathy

\section{Background}

Calcification of the ligamentum flavum (CLF) is a rare disease mainly occurring in the cervical spine (Miyasaka et al. 1983). CLF results in posterior spinal cord compression, which may cause myelopathy and successive neurological deficits. It mostly occurs in the Asian population (Ahn et al. 2014). However, several cases in Caucasian patients have been reported (Khan et al. 2005; Ugarriza et al. 2001). The exact pathophysiology is unknown, although findings from multiple case-reports describing CLF suggest that CLF could be a rare manifestation of the deposition of calcium pyrophosphate dehydrate crystals (CPPD) (Berghausen et al. 1987; Brown et al. 1991; Giulioni et al. 2007; Seki et al. 2013). Clinical manifestation usually starts with a loss of vibration, proprioception and functional gait worsened by motor weakness and paresthesia. To distinguish CLF from other causes of dorsal spinal cord compression, radiological imaging, cerebral spinal fluid (CSF) analysis and histological tissue examination are needed. In this report, we describe a case

\footnotetext{
*Correspondence: r.dammers@erasmusmc.nl

${ }^{4}$ Department of Neurosurgery, Erasmus MC Sophia Children's Hospital,'s Gravendijkwal 230, Office Hs-114, PO Box 2040, 3000 CA Rotterdam, The Netherlands

Full list of author information is available at the end of the article
}

of cervical and thoracic myelopathy due to extensive CLF in a 63-year-old Caucasian woman and its treatment.

\section{Case report \\ Case}

A 63-year-old female presented with progressive pins-andneedles sensations in both hands over the past 3 years, worsened by tingling and burning pain in both lower extremities since 4 weeks. Physical examination revealed bilateral hypesthesia of all digits of the hands and loss of vibration sense up to the clavicle following the dermatomes $\mathrm{C} 5-\mathrm{C} 8$. The biceps, triceps and brachioradialis reflexes were all slightly increased. For lower extremities physical examination showed changing hypesthesia on the lateral sides of both legs and feet with a loss in vibration up to the knee. The knee and ankle jerk reflexes were slightly increased with an indifferent plantar reflex bilaterally. There were no changes in muscle tone and Lhermitte's sign was positive. MRI showed an intraspinal extradural compressive mass extending from $\mathrm{C} 2$ to Th3 posterior of the spinal cord. Spinal cord was compressed at the level of C5/6 and C6/7 (Fig. 1). The lesion was hypointense on T1and T2-weighted MRI sequences and gadolinium contrast showed a heterogeneous uptake. To obtain spinal cord decompression and pathological tissue, a laminectomy at 

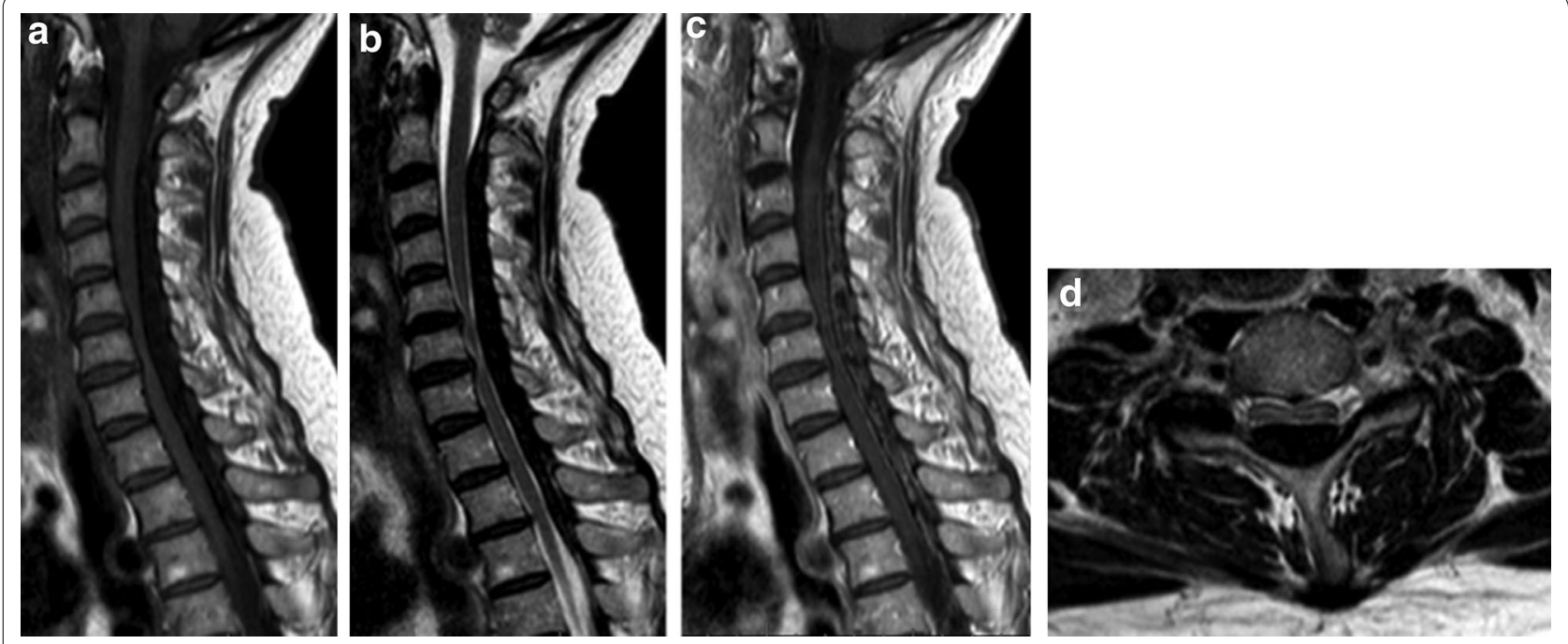

Fig. 1 Sagittal MRI in T1- (a) and T2- (b) weighted sequences. cT1-weighted sequence with heterogeneous gadolinium uptake. $\mathbf{d}$ Extensive spinal cord compression at $\mathrm{C} 6$

the level of C6 was performed. The lesion consisted of a white, hard granulated substance directly located anterior to the posterior neural arch intertwined with the ligamentum flavum lying on top of a rigid thickened dura mater. Tissue was sent in for histologic examination. CSF was extracted for further analysis. Directly post-laminectomy, neurological examination was as preoperatively. Postoperatively, an additional computed tomography scan (CTscan) was made to distinguish CLF from ossification of the ligamentum flavum (OLF) and revealed hyperdens oval nodular lesions posterior of the myelum, only partially connected with the laminae (Figs. 2, 3).

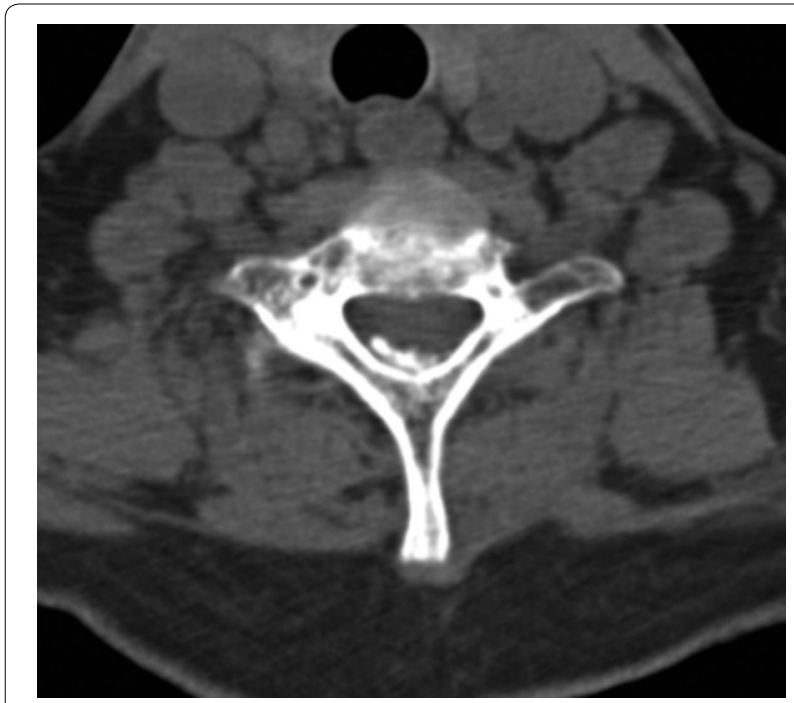

Fig. 2 Axial CT-scan showing a hyperdense dorsal intraspinal extradural lesion at C7

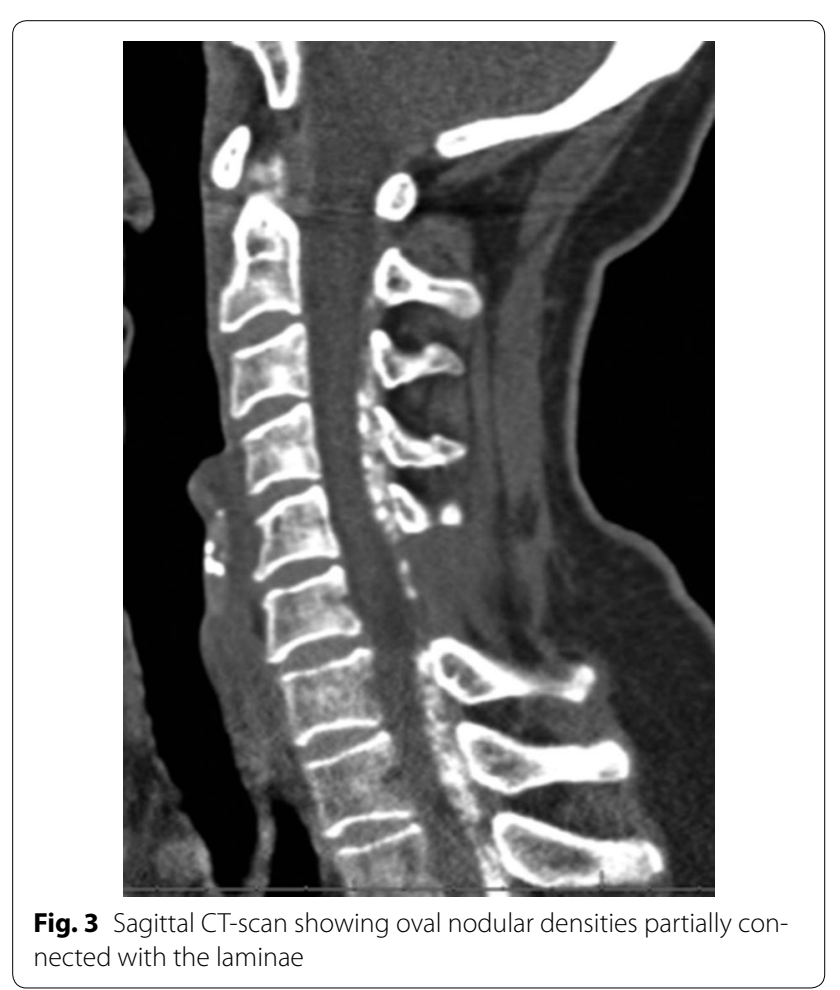

\section{Histology}

Histology showed ligamentous and cartilage tissue containing extensive dystrophic calcifications intertwined with ligamentum flavum without traces of old blood or mature bone formation (Fig. 4). Histologically there were no signs of lymphoma, nor traces of mycobacterium 

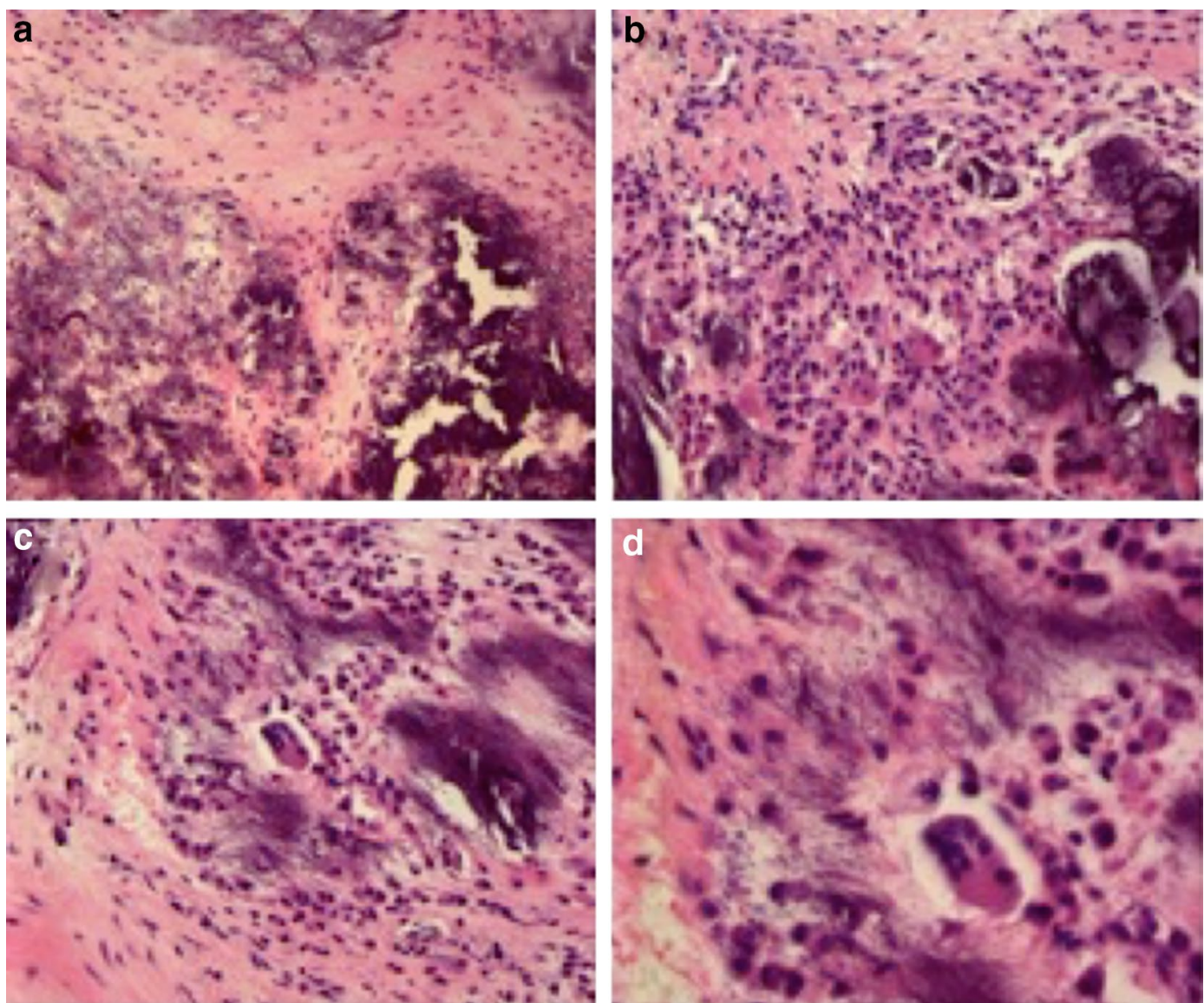

Fig. 4 Evacuated lesion with HE staining and magnification $\times 200(\mathbf{a}, \mathbf{b}, \mathbf{c})$ and $\times 400(\mathbf{d})$

tuberculosis, other bacteria or fungi. CSF analysis showed no indications of lymphoma or infection either.

\section{Follow-up}

One-month MRI follow-up showed no progression of the lesion and a clear decompression of the spinal cord at the operated level (Fig. 5). Eight months later, hypesthesia of all digits of the right hand and in lesser extend of the left hand had become less, reflexes of her upper extremities normalized. The tingling sensations and reflexes in her lower extremities persisted.

\section{Discussion}

Dorsal spinal cord compression can be caused by different pathological conditions. MRI imaging is important to differentiate from neoplasm, meningioma, lymphoma and chronic calcified epidural hematoma (Boutarbouch et al. 2008; Matsui et al. 2014; Seo et al. 2014; Zhong et al. 2011). To exclude pachymeningitis, CFS analysis is needed (Senapati et al. 2014). Sagittal CT-imaging revealed oval nodular densities, partially connected with the laminae. This distinguishes CLF from OLF since OLF arises from the lamina and moves inward towards the midline (Miyasaka et al. 1983). The exact pathophysiology of CLF is yet to be discovered. Seki et al. described a large calcified mass in the ligamentum flavum level L4/5 and after resection, additional analyses showed the mass mostly consisted of calcium triphosphate and calcium phosphate with degenerative changes possibly involved in the formation of this mass (Seki et al. 2013). Other reports describing cervical CLF also mention nodular deposition of calcium pyrophosphate dehydrate crystals in the ligamentum flavum (Berghausen et al. 1987; Brown et al. 1991; Cabre et al. 2001). CPPD crystal formation can be sporadic or hereditary and may be related to metabolic diseases such as hypophosphatemia, hypothyroidism, hyperparathyroidism and hemochromatosis (Berghausen et al. 1987; Riccio et al. 2016). Calcium crystal deposition in the ligamentum flavum seems to progress with a reduction in elastic fibers, an increase in collagen fibrils and migration of hypertrophic chondrocytes (Mwaka et al. 2009). This indicates that CPPD may be a consequence of degenerative changes in the ligamentum flavum, which might explain the broad extension of the lesion in our 


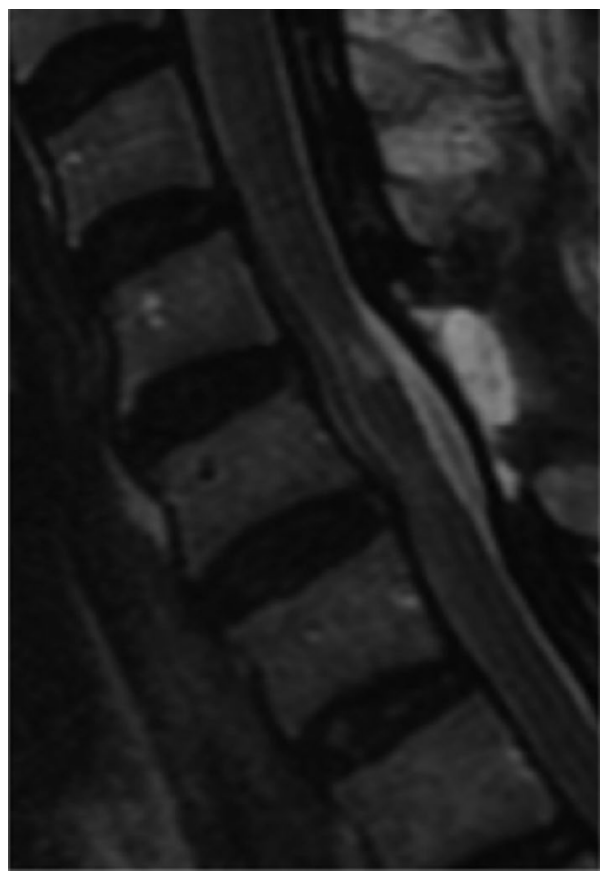

Fig. 5 Sagittal MRI in T2-weighted sequence showing decompression of the spinal cord after laminectomy

case. Recent research shows that mechanical load may be a contributing factor to CLF. They found that mechanical load induces the differentiation of ligamentum flavum cells leading to calcium depositions (Chao et al. 2016).

The only treatment for CLF is surgical decompression of the spinal cord (Ahn et al. 2014; Delgado-Lopez et al. 2007; Inoue et al. 2013; Khan et al. 2005; Sun et al. 2014; Yuan et al. 2014). The right method of decompression, we believe, is laminectomy. A retrospective study of thoracic OLF showed that laminectomy with fusion had a better outcome than laminoplasty (Li et al. 2006). Such a large study has not been executed for CLF. One study shows good clinical outcome after endoscopic partial laminectomy (Yabuki and Kikuchi 2008). Since the diagnoses was uncertain and we considered it to be a lymphoma we decided to perform a laminectomy of only C6 first in order to decompress the spinal cord where it showed myelopathy and to obtain tissue for histology. Since clinical outcome improved, we, in consolation with our patient, decided to only further decompress the spinal cord should neurological deterioration occur in the future. Clinical symptoms were mild and stable and no further decompression was there for deemed necessary.

\section{Conclusion}

Although rare, CLF should be considered as a possible diagnosis of extensive dorsal spinal cord compression. It is important to recognize and treat CLF at an early stage, since timely decompression results in better neurologic outcome.

\section{Abbreviations \\ CLF: calcification of the ligamentum flavum; CSF: cerebrospinal fluid; CT-scan: computed tomography scan; MRI: magnetic resonance imaging; OLF: ossifica- tion of the ligamentum flavum; CPPD: calcium pyrophosphate dihydrate crystal deposition disease.}

\section{Authors' contribution}

MW, SBH and RD are the treating physicians of the patient and conceptualized the manuscript. MJK made the histopathological diagnosis. MR and JKHS wrote the manuscript after which all other authors edited the manuscript to its current form. All authors read and approved the final manuscript.

\section{Author details \\ ${ }^{1}$ Department of Neurosurgery, Erasmus MC, Rotterdam, The Netherlands. ${ }^{2}$ Department of Neurology, Albert Schweitzer Ziekenhuis, Dordrecht, The Netherlands. ${ }^{3}$ Department of Pathology, Erasmus MC, Rotterdam, The Nether- lands. ${ }^{4}$ Department of Neurosurgery, Erasmus MC Sophia Children's Hospital, 's Gravendijkwal 230, Office Hs-114, PO Box 2040, 3000 CA Rotterdam, The Netherlands.}

\section{Competing interests}

The authors declare that they have no competing interests.

\section{Informed consent}

The patient has consented to submission of this case report to the journal. For this, she granted us permission to access her medical data. The data were treated respecting the institutional medical ethical committee guidelines, therewith approving of the case report.

Received: 25 June 2016 Accepted: 2 November 2016

Published online: 07 November 2016

\section{References}

Ahn DK, Lee S, Moon SH, Boo KH, Chang BK, Lee Jl (2014) Ossification of the ligamentum flavum. A sian Spine J 8(1):89-96

Berghausen EJ, Balogh K, Landis WJ, Lee DD, Wright AM (1987) Cervical myelopathy attributable to pseudo- gout: case report with radiologic, histologic, and crystallographic observations. Clin Orthop Relat Res 214:217-221

Boutarbouch M, Arkha Y, Rifi L, Derraz S, El Ouahabi A, El Khamlichi A (2008) Intradural cervical inflammatory pseudotumor mimicking epidural hematoma in a pregnant woman: case report and review of the literature. Surg Neurol 69(3):302-305

Brown TR, Quinn SF, D'Agostino AN (1991) Deposition of calcium pyrophosphate dihydrate crystals in the ligamentum flavum: evaluation with MR imaging and CT. Radiology 178(3):871-873

Cabre P, Pascal-Moussellard H, Kaidomar S, Bucki B, Bardin T, Smadja D, Arfi S (2001) Six cases of cervical ligamentum flavum calcification in Blacks in the French West Indies. Joint Bone Spine 68(2):158-165

Chao YH, Huang SY, Yang RC, Sun JS (2016) Tissue transglutaminase is involved in mechanical load-induced osteogenic differentiation of human ligamentum flavum cells. Connect Tissue Res 57(4):307-318

Delgado-Lopez PD, Martin-Velasco V, Castilla-Diez JM, Velasco-Oses A (2007) Symptomatic cervical stenosis due to calcification of the ligamentum flavum after mild cervical trauma. Neurocirugia (Astur) 18(2):141-146

Giulioni M, Zucchelli M, Damiani S (2007) Thoracic myelopathy caused by calcified ligamentum flavum. Joint Bone Spine 74(5):504-505

Inoue H, Seichi A, Kimura A, Endo T, Hoshino Y (2013) Multiple-level ossification of the ligamentum flavum in the cervical spine combined with calcification of the cervical ligamentum flavum and posterior atlantoaxial membrane. Eur Spine J 22(Suppl 3):S416-\$420 
Khan MH, Smith PN, Donaldson WF III (2005) Acute quadriparesis caused by calcification of the entire cervical ligamentum flavum in a white femalereport of an unusual case and a brief review of the literature: case report. Spine (Phila Pa 1976) 30(22):E687-E691

Li F, Chen Q, Xu K (2006) Surgical treatment of 40 patients with thoracic ossification of the ligamentum flavum. J Neurosurg Spine 4(3):191-197

Matsui H, Imagama S, Ito Z, Ando K, Hirano K, Tauchi R, Muramoto A Matsumoto T, Ishiguro N (2014) Chronic spontaneous lumbar epidural hematoma simulating extradural spinal tumor: a case report. Nagoya J Med Sci 76(1-2):195-201

Miyasaka K, Kaneda K, Sato S, Iwasaki Y, Abe S, Takei H, Tsuru M, Tashiro K, Abe H, Fujioka Y (1983) Myelopathy due to ossification or calcification of the ligamentum flavum: radiologic and histologic evaluations. AJNR Am J Neuroradiol 4(3):629-632

Mwaka ES, Yayama T, Uchida K, Kobayashi S, Kokubo Y, Nakajima H, Sato R, Orwotho NT, Baba H (2009) Calcium pyrophosphate dehydrate crystal deposition in the ligamentum flavum of the cervical spine: histopathological and immunohistochemical findings. Clin Exp Rheumatol 27(3):430-438

Riccio AR, Entezami P, Giuffrida A, Dowling J, Forrest G, German JW (2016) Minimally invasive surgical management of thoracic ossification of the ligamentum flavum associated with X-linked hypophosphatemia. World Neurosurg. doi:10.1016/j.wneu.2016.07.076

Seki S, Kawaguchi Y, Ishihara H, Oya T, Kimura T (2013) Lumbar spinal stenosis due to a large calcified mass in the ligamentum flavum. Asian Spine J 7(3):236-241
Senapati SB, Mishra SS, Das S, Parida DK, Satapathy MC (2014) Cranio cervical tuberculous hypertrophic pachymeningitis. Surg Neurol Int 5:52

Seo JY, Ha KY, Kim MU, Kim YC, Kim YH (2014) Spinal cord compression by B-cell lymphoma, unclassifiable, with features intermediate between diffuse large B-cell lymphoma and Burkitt lymphoma in a patient seropositive for human immunodeficiency virus: a case report. J Med Case Rep 8:324

Sun J, Zhang C, Ning G, Li Y, Li Y, Wang P, Feng S (2014) Surgical strategies for ossified ligamentum flavum associated with dural ossification in thoracic spinal stenosis. J Clin Neurosci 21(12):2102-2106

Ugarriza LF, Cabezudo JM, Porras LF, Rodriguez-Sanchez JA (2001) Cord compression secondary to cervical disc herniation associated with calcification of the ligamentum flavum: case report. Neurosurgery 48(3):673-676

Yabuki S, Kikuchi S (2008) Endoscopic surgery for cervical myelopathy due to calcification of the ligamentum flavum. J Spinal Disord Tech 21(7):518-523

Yuan Q, Zheng S, Tian W (2014) Computer-assisted minimally invasive spine surgery for resection of ossification of the ligamentum flavum in the thoracic spine. Chin Med J (Engl) 127(11):2043-2047

Zhong W, Chen H, Huang S, You C (2011) Cervical en-plaque epidural meningioma. Neurol India 59(1):132-134

\section{Submit your manuscript to a SpringerOpen ${ }^{\circ}$ journal and benefit from:}

- Convenient online submission

- Rigorous peer review

- Immediate publication on acceptance

- Open access: articles freely available online

- High visibility within the field

- Retaining the copyright to your article

Submit your next manuscript at $\boldsymbol{\nabla}$ springeropen.com 